This item was submitted to Loughborough's Research Repository by the author.

Items in Figshare are protected by copyright, with all rights reserved, unless otherwise indicated.

\title{
Potential for LED solar simulators
}

PLEASE CITE THE PUBLISHED VERSION

http://dx.doi.org/10.1109/PVSC.2013.6744248

\section{PUBLISHER}

(c) IEEE

\section{VERSION}

AM (Accepted Manuscript)

\section{PUBLISHER STATEMENT}

This work is made available according to the conditions of the Creative Commons Attribution-NonCommercialNoDerivatives 4.0 International (CC BY-NC-ND 4.0) licence. Full details of this licence are available at: https://creativecommons.org/licenses/by-nc-nd/4.0/

\section{LICENCE}

CC BY-NC-ND 4.0

\section{REPOSITORY RECORD}

Plyta, Foteini, Thomas R. Betts, and Ralph Gottschalg. 2019. "Potential for LED Solar Simulators". figshare. https://hdl.handle.net/2134/17664. 


\title{
Potential for LED Solar Simulators
}

\author{
Foteini Plyta, Thomas R. Betts and Ralph Gottschalg
}

Centre for Renewable Energy Systems Technology (CREST), School of Electronic, Electrical and Systems Engineering, Loughborough University, Loughborough, Leicestershire, LE11 3TU, UK

\begin{abstract}
LED solar simulators have been discussed recently as a potential next generation solar simulator. This contribution evaluates the possibilities of generating a light field of appropriate spectrum with good uniformity. LEDs have very different optical characteristics compared to standard lights and this needs to be considered in the optical design. The aim in this paper is to achieve a close spectral match to the AM1.5 solar spectrum from $350 \mathrm{~nm}$ to $1300 \mathrm{~nm}$. A total irradiance of $1000 \mathrm{~W} / \mathrm{m}^{2}$ needs to be acquired. Additionally, the non-uniformity of light needs to be equal to or less than $1 \%$. The key to mix spectra and achieve the desired intensity and uniformity is the optics. This paper evaluates different optical layouts to assess the potential for fully LED based solar simulators. The TIRs perform better collecting more light than other optics tested.
\end{abstract}

Index Terms-Light Emitting Diodes (LEDs), Solar Simulator, Characterization, Optical Design, Uniformity, Spectral match.

\section{INTRODUCTION}

As solar installations are constantly increasing worldwide, high quality characterization of photovoltaic modules for accurate power rating and energy yield prediction measurements is critical and more essential than ever. Most manufacturers offer a 20-25 year warranty for their panels. However, if the characterization of the modules is not precise and their quality does not meet the promised levels, the lost revenue of an investment can be large. Therefore, the need for a class AAA solar simulator is great.

The main sources of measurement uncertainty are the spectral match, the non-uniformity of light and the reference cell. They can increase the measurement uncertainty significantly. In order to minimize two main uncertainty factors related to solar simulators, the spectral mismatch and the non-uniformity of light, a close spectral match and a good uniformity of light need to be acquired.

It is being argued that LEDs are excellent candidates as light sources in solar simulators as they have the potential to result in a class AAA system, regarding the IEC standards [1]. It will be shown that one main advantage in using LEDs as main light sources in a solar simulator is their capability to achieve a close spectral match to the AM1.5 solar spectrum, which improves the measurement accuracy of the solar simulator. They could also be regulated to meet any other desired Air Mass as long as realistic intensities are required. Their effectiveness in achieving variable light intensities and variable output spectra provides more flexibility in reproducing realistic environmental conditions in the solar simulator [2].

During the prototype development at CREST, it became clear that the key to a successful project would be the optics. LED solar simulators proposed so far have followed a diffuse approach with regard to the light distribution [2] - [9]. In cases where comparative characterization of solar panels is sufficient a diffuse solar simulator can be used. However, in test laboratories, where each measurement is independent and characterization is performed on a case-by-case basis, uncertainties introduced by diffuse light do not allow for an accurate measurement. The reflections taking place cannot be predicted. As a result, the current is often overestimated due to the lack of calibration. Therefore, a directed beam approach needs to be followed.

The irradiance on an illuminated area is decreasing as the light source is moving away from it following the inverse square law. Staying close to the light source provides good collection efficiency but the uniformity and color matching can be very poor. Hence, the use of optical elements may be beneficial. It is crucial that directionality of light is preserved.

The effect of optics in the uniformity and collection efficiency of light is to be investigated here. It has been decided that non-uniformity of light should be less than $1 \%$ to have half the non-uniformity specified in [1]. The irradiance should reach $1000 \mathrm{~W} / \mathrm{m}^{2}$ to allow for standard test conditions (STC) measurements. Different design options will be evaluated and their success in meeting those goals will be discussed.

However, reaching the desired irradiance and nonuniformity levels is not the only prerequisite for a high quality measurement unit. A close spectral match to the AM1.5 solar spectrum is equally crucial. The potential of achieving a class A spectral match using LEDs across the $350 \mathrm{~nm}-1300 \mathrm{~nm}$ range, to cover for the spectral response of different PV technologies, will be presented.

\section{Collection EFFiciency And Uniformity EVAluation Of DifFERENT PRIMARY OPTICS}

The aim is to design, as a proof of concept, a medium area measurement unit. Thus, the illuminated area was chosen to be $32 \mathrm{~cm} \mathrm{x} 32 \mathrm{~cm}$. The irradiance patterns of the various optical designs were calculated using an optical engineering software called FRED by photon engineering and the collection efficiency and non-uniformity calculations were performed in Matlab.

A wide variety of high power LEDs is available on the market. Different LEDs of different layouts were chosen to test their effectiveness in collection efficiency and uniformity of light. The three layouts chosen were LED dies on their own, packaged LEDs, i.e. the die with a dome on top and packaged LEDs with multiple dies. The dimensions of these LED types are different. Therefore, the number of LEDs that can fit in a 


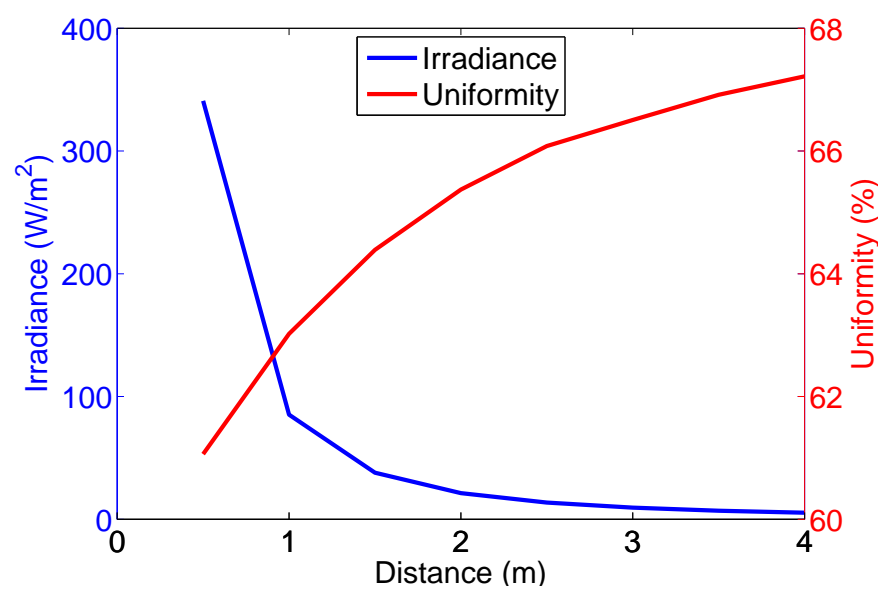

Fig. 1. The irradiance decreases and the uniformity increases with distance.

certain area changes with the type of LEDs used.

Primary optics, which are placed directly on the LED, aim at collimating the light and at increasing the collection efficiency. A common angle of divergence of LEDs is \pm 60 degrees which can be reduced to \pm 4 degrees with the usage of primary optics. The challenge then is to mix and homogenize the light. The optical elements chosen in this study were standard optics designed for LEDs. More specifically, an aspheric lens, a parabolic mirror (PM) and a total internal reflector (TIR) were the main primary optics, which were considered. The aspheric lens was chosen for its simple design and collimating capabilities. Both the parabolic mirror and the TIR were chosen for the high collimation and collection efficiencies they can result to. The diameters of the optics are different resulting in a different number that can fit in a specified 'lamp' area.

Primarily the goal was to populate a specified area with different combinations of LEDs and primary optics and measure the irradiance and the non-uniformity of light on an illuminated area positioned at various distances away from the lamp. All the simulations were carried out for distances $0.5 \mathrm{~m}$ to $4 \mathrm{~m}$ in $0.5 \mathrm{~m}$ intervals. As it can be seen in Fig. 1 the irradiance decreases radically and the uniformity increases substantially within the first meter and then the graphs level off. Therefore, the distance of $1 \mathrm{~m}$ was chosen for the comparison of the performance of the different optical layouts in order to compensate between the irradiance and uniformity levels.

Different 'lamp' areas were chosen to determine the size of the lamp and the number of optical elements required to produce $1000 \mathrm{~W} / \mathrm{m}^{2}$. Initially a $10 \mathrm{~cm} \times 10 \mathrm{~cm}$ 'lamp' area was chosen to test whether the LEDs that would fit on it could produce $1000 \mathrm{~W} / \mathrm{m}^{2}$. All components were placed equidistantly. The number of LEDs that fit in a specific area can be seen in Fig. 2.

Despite the large number of LED dies that the lamp comprises of when no optics are used, it can be clearly seen in Fig. 3 that the irradiance level of $1000 \mathrm{~W} / \mathrm{m}^{2}$ (line in blue) cannot be reached. On the other hand, the usage of primary optics increases the collection efficiency resulting in higher

\begin{tabular}{|c|c|c|c|c|}
\hline \multicolumn{2}{|c|}{ Lamp Size } & $10 \mathrm{~cm} \times 10 \mathrm{~cm}$ & $20 \mathrm{~cm} \times 20 \mathrm{~cm}$ & $32 \mathrm{~cm} \times 32 \mathrm{~cm}$ \\
\hline \multirow{3}{*}{ No Optics } & LED Dies & 2500 & 10000 & 25600 \\
\hline & Packaged LEDs & 484 & 2025 & 5184 \\
\hline & $\begin{array}{l}\text { Packaged LEDs- } \\
\text { Multiple Dies }\end{array}$ & 120 & 500 & 1280 \\
\hline \multirow{3}{*}{$\begin{array}{l}\text { Aspheric } \\
\text { Lens }\end{array}$} & LED Dies & 169 & 625 & 1600 \\
\hline & Packaged LEDs & 169 & 625 & 1600 \\
\hline & $\begin{array}{l}\text { Packaged LEDs- } \\
\text { Multiple Dies }\end{array}$ & 120 & 500 & 1280 \\
\hline \multirow{3}{*}{$\begin{array}{l}\text { Parabolic } \\
\text { Mirror }\end{array}$} & LED Dies & 25 & 121 & 289 \\
\hline & Packaged LEDs & 25 & 121 & 289 \\
\hline & $\begin{array}{l}\text { Packaged LEDs- } \\
\text { Multiple Dies }\end{array}$ & 25 & 121 & 289 \\
\hline \multirow{3}{*}{$\begin{array}{l}\text { Total Internal } \\
\text { Reflector }\end{array}$} & LED Dies & 9 & 49 & 121 \\
\hline & Packaged LEDs & 9 & 49 & 121 \\
\hline & $\begin{array}{l}\text { Packaged LEDs- } \\
\text { Multiple Dies }\end{array}$ & 9 & 49 & 121 \\
\hline
\end{tabular}

Fig. 2. Populations of different optical elements on different lamp areas.

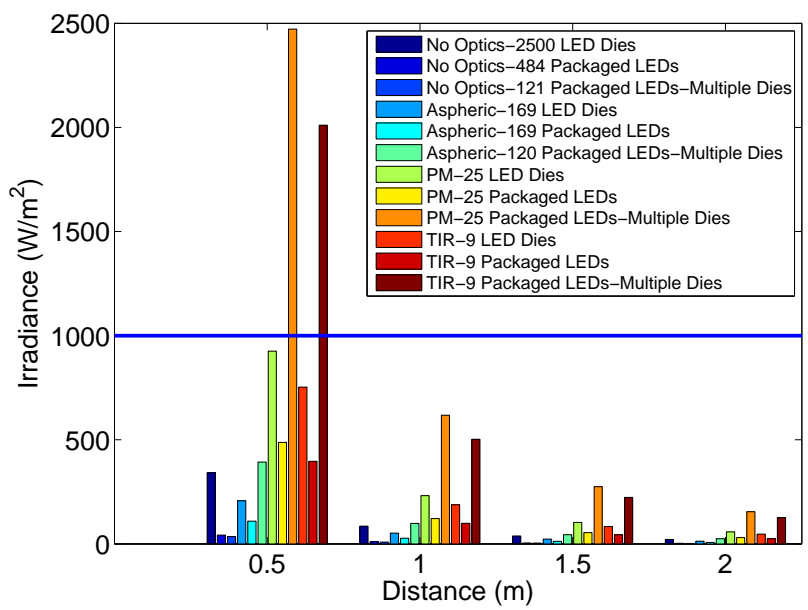

Fig. 3. Irradiance levels of different optical layouts positioned in a $10 \mathrm{~cm} \mathrm{x}$ $10 \mathrm{~cm}$ area.

irradiance levels. However, primary optics are larger in size and the number of elements positioned in a $10 \mathrm{~cm} \times 10 \mathrm{~cm}$ lamp area are small to result in the desired irradiance levels. Therefore, larger lamp areas were tested as well as shown in Fig. 4 and Fig. 5.

All the cases are considered ideal and it is assumed that no losses occur. It is clear that aspheric lenses do not perform well enough and will not be considered further as they only reach $1000 \mathrm{~W} / \mathrm{m}^{2}$ when the size of the lamp is $32 \mathrm{~cm} \times 32 \mathrm{~cm}$ and the number of optical elements needed is much higher compared to the cases of parabolic mirrors and TIRs. Furthermore, once the optical losses are calculated the aspheric lenses will no longer meet the requirements. Thus, a higher collimation is desired to achieve higher irradiance levels.

Both the parabolic mirrors and the TIRs managed to reach $1000 \mathrm{~W} / \mathrm{m}^{2}$ for $20 \mathrm{~cm} \times 20 \mathrm{~cm}$ and $32 \mathrm{~cm} \times 32 \times \mathrm{m}$ lamp areas and they perform much better when positioned on top of the packaged LEDs with multiple dies, which are more powerful. However, the parabolic mirrors have smaller diameters than the TIRs resulting in more elements populating the lamp area. 


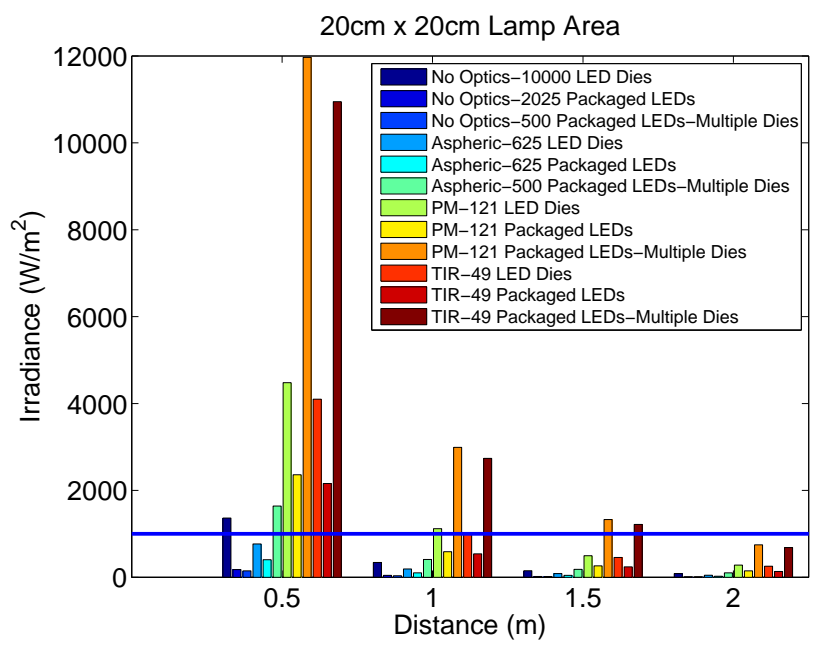

Fig. 4. Irradiance levels of different optical layouts positioned in a $20 \mathrm{~cm} x$ $20 \mathrm{~cm}$ area.

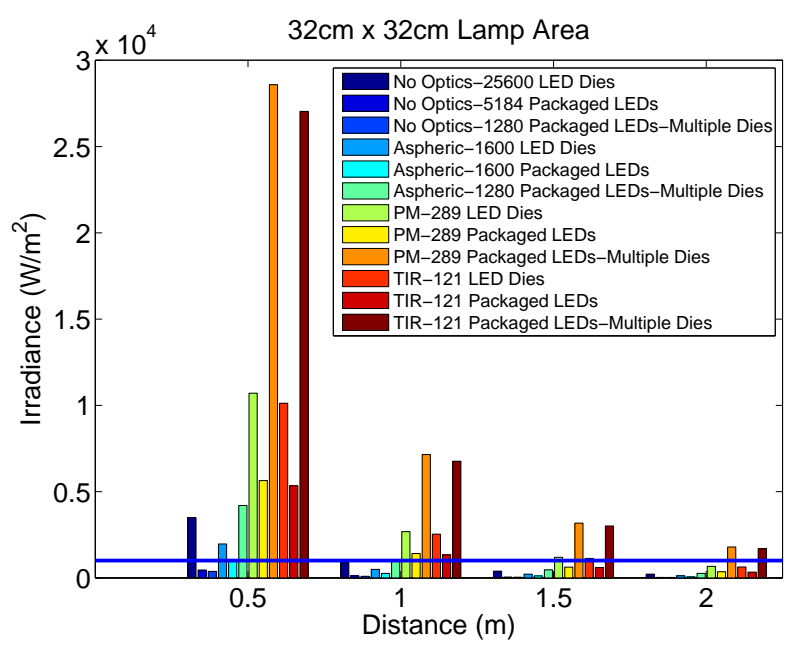

Fig. 5. Irradiance levels of different optical layouts positioned in a $32 \mathrm{~cm} \mathrm{x}$ $32 \mathrm{~cm}$ area.

Therefore, the TIRs perform better than parabolic mirrors when the same number of elements is used as shown in Fig.6.

The irradiance levels acquired by the TIRs show that when a larger number of LEDs is used the irradiance is sufficient even after all losses are calculated. The losses that need to be taken into account are thermal, optical and driver ones. It can be seen in Fig. 7 that even after 50\% losses were considered the TIRs still offered irradiance levels above $1000 \mathrm{~W} / \mathrm{m}^{2}$ except for packaged LEDs of single die. This is due to their lower power outputs.

Therefore, the most efficient primary optics which will be considered for the non-uniformity analysis are the TIRs. As it has been mentioned above, the desired illuminated area with non-uniformity levels of $1 \%$ was chosen to be $32 \mathrm{~cm} \times 32 \mathrm{~cm}$ to be sufficient for medium area modules. Different lamp sizes and different LED positions were simulated to calculate the non-uniformity. Fig. 8 shows the variation of non-uniformity

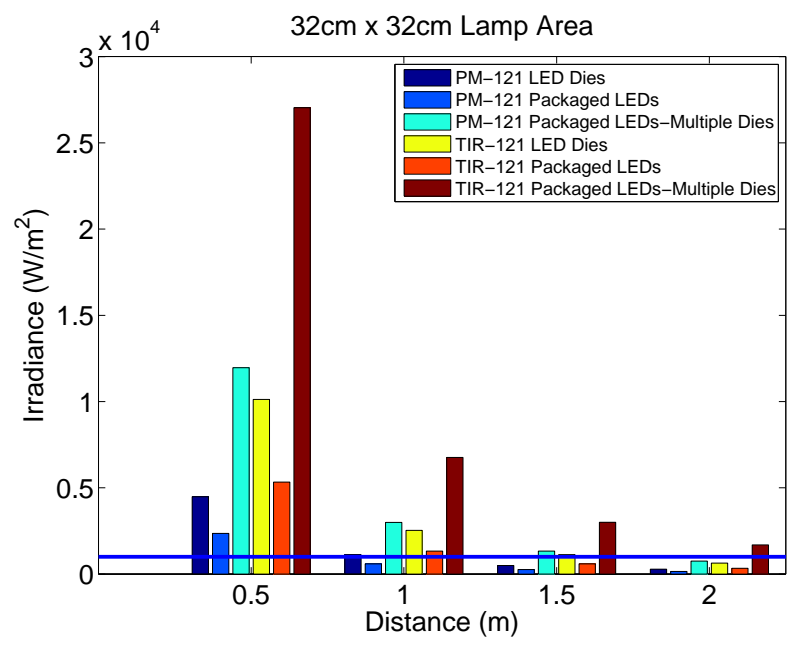

Fig. 6. Comparison of the performance of PMs and TIRs positioned in a $32 \mathrm{~cm} \times 32 \mathrm{~cm}$ area.

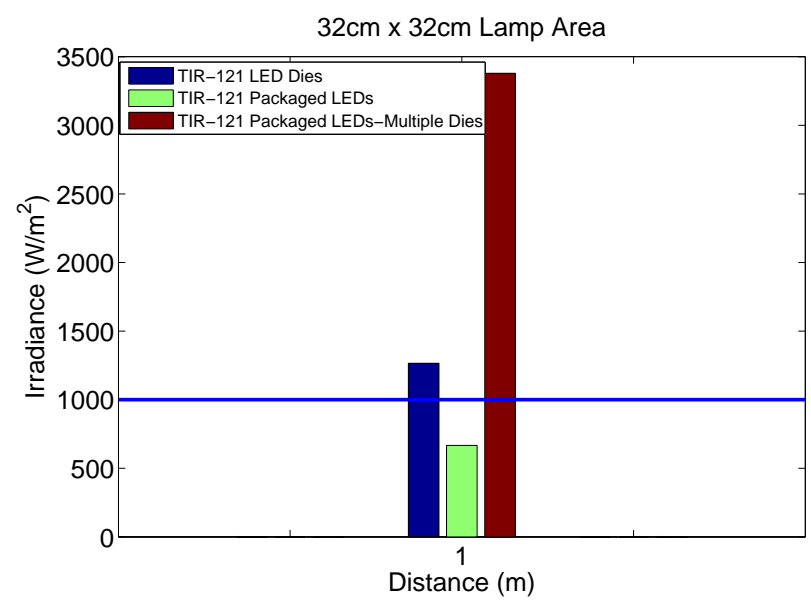

Fig. 7. Irradiance levels of TIRs with $50 \%$ losses.

and of the size of the lamp edge with different numbers of LEDs. The higher the number of LEDs, the lower the non-uniformity percentage achieved. However, the area of the lamp increases significantly with the increase of the number of LEDs.The simulations showed that a $1.5 \%$ non-uniformity over a $32 \mathrm{~cm} \times 32 \mathrm{~cm}$ illuminated area can be reached for lamp sizes greater than $700 \mathrm{~cm} \times 700 \mathrm{~cm}$ when the LEDs were positioned at a $1 \mathrm{~mm}$ distance from each other. More distances between the LEDs were also simulated as the light mixing improves. However, the increase of distance results in the reduction of LEDs that fit in a specific area. As a result the non-uniformity did not improve for greater LED distances.

\section{Spectral MATCH}

A selection of LEDs available on the market was chosen to simulate the solar spectrum. An optimization method was followed to specify which and how many of those LEDs lead to a class A spectral match. The main objective is to minimize the difference between the theoretical AM1.5 solar 


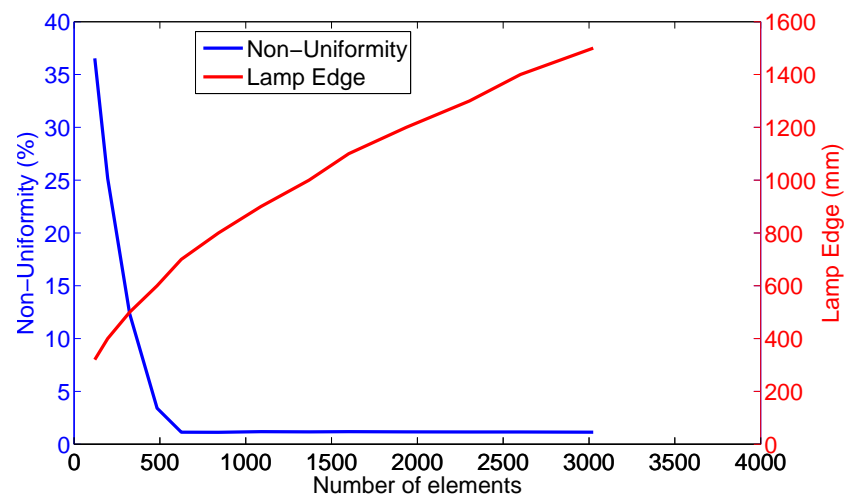

Fig. 8. Non-Uniformity and lamp side against the number of elements.

spectrum and the spectrum constructed by the LEDs by using as fewer LEDs as possible. The standards specify a class A spectral match if it is within the 0.75-1.25 range for 5 different $100 \mathrm{~nm}$ bins and a $200 \mathrm{~nm}$ bin [1]. Two different optimization techniques need to be followed to solve different aspects of the problem. The first one is the determination of the number of LEDs per wavelength for a given set of wavelengths and the second one is the determination of the best combination of wavelengths. They both depend on each other. The second optimization method chooses a combination of LEDs for every iteration and then the first optimization method determines how many of those LEDs should be used and what the best possible fit to the target spectrum should be.

The accuracy of the result depends on the precision of the algorithm used. Therefore, a superior optimization method should be used to determine the optimum solution. The simulations are very computing intensive due to the great number of possible combinations which can be calculated. The number of possible wavelength combinations increases exponentially with the number of LEDs. It becomes clear that this problem cannot be solved analytically as it is time consuming.

The optimization method chosen for the first objective is the $X^{2}$ (chi-squared) algorithm while the optimization method chosen for the second objective is the genetic algorithm. These algorithms were chosen for their speed, accuracy and reliability. However, the genetic algorithm has many internal parameters that require to be set and they are specific to each problem. Therefore, in order to determine the best values for all those parameters a lot of trial and error simulations are needed.

Some initial results showed that a class A spectral match can be achieved by using 32 different wavelengths across the $350 \mathrm{~nm}-1300 \mathrm{~nm}$ range as shown in Fig. 9.

\section{CONCLUSIONS}

Solar simulators are very important characterization tools for the performance of photovoltaic modules. The techniques used so far employed different types of light sources such as halogen and xenon lamps. Efforts have been made so far to build LED solar simulators due to the better performance

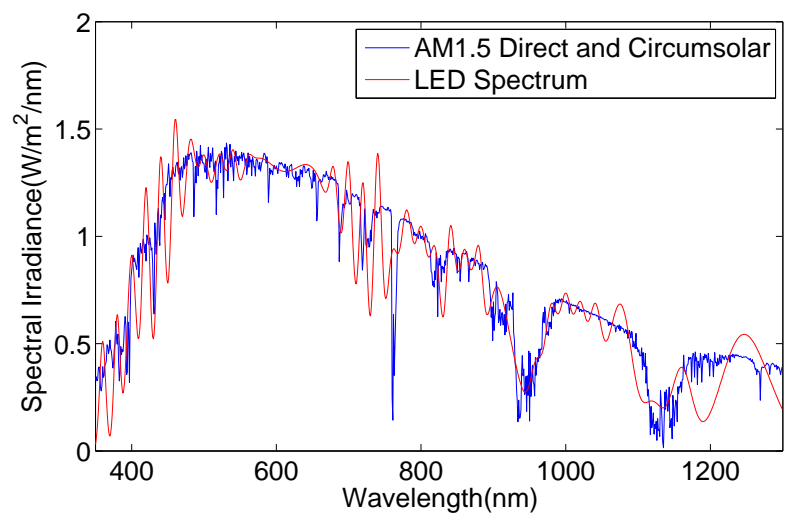

Fig. 9. Class A spectral match is achieved with 32 LEDs of different wavelengths across the $350 \mathrm{~nm}-1300 \mathrm{~nm}$ range.

of LEDs and their potential of achieving a very good spectral match as well as their capability of simulating different spectra by varying their output [2] - [9]. However, no fully based LED solar simulator has been presented so far following the directionality approach using optics.

Several optical layouts using different types of LEDs and primary optics were examined to evaluate the irradiance levels, the non-uniformity results and the spectral match which can be achieved in an effort to build a class AAA LED solar simulator. To achieve a cost effective optical design that meets the criteria of an AAA LED solar simulator, the collection efficiency should be maximized. As a result less LEDs and optical elements will be used to achieve the desired intensity of $1000 \mathrm{~W} / \mathrm{m}^{2}$.

It is shown in this study that the usage of primary optics is of great importance if the desired irradiance levels are to be reached without using a large number of LEDs. A distance of $1 \mathrm{~m}$ between the illuminated area and the LEDs was chosen in an effort to find a balance between the collection efficiency and the non-uniformity of light. The collection efficiency proved to be satisfactory when the parabolic mirrors and total internal reflectors were used as primary optics as they offer high collimation of light. The TIR was chosen as it performed better.

A non-uniformity of $1.5 \%$ over a $32 \mathrm{~cm} \mathrm{x} 32 \mathrm{~cm}$ illuminated area was only reached for lamp sizes greater than $700 \mathrm{~cm} \mathrm{x}$ $700 \mathrm{~cm}$ for a $1 \mathrm{~mm}$ distance between LEDs. However, even greater distances did not improve the non-uniformity as the number of LEDs that fit in the same area reduces. These results lead to the conclusion that in order to keep the lamp size smaller secondary optics will need to be employed to homogenize the light output of the LEDs. The usage of TIRs is very crucial since the light input of secondary optics needs to be highly collimated. On the other hand the initial results for the spectral match are very promising leading to a class A using 32 different wavelengths.

In conclusion, the key to a successful project is that powerful primary optics are used to maximize the collection 
efficiency and collimation of light. The usage of secondary optics will determine the good mixing and uniformity of light whereas the LEDs' wavelengths and number of each wavelength will result in a class A spectral match.

\section{REFERENCES}

[1] IEC 60904-9 Ed.2, Photovoltaic devices Part 9: Solar simulator performance requirements, 2007.

[2] M.Bliss, T. R. Betts and R. Gottschalg, Advantages in using LEDs as the main light source in solar simulators for measuring PV device characteristics art. No. 704807, Reliability of Photovoltaic Cells, Modules, Components, and Systems, col.7048, pp. 4807-4807, 2008.

[3] S. Kohraku and K. Kurokawa, A fundamental experiment for discretewavelength LED solar simulator, Solar Energy Materials and Solar Cells, vol. 90, pp. 3364-3370,2006.

[4] R. Grischke, J. Schmidt, H. Albert, A. Laux, A. Metz, U. Hilsenberg and J. Gentischer, LED flasher arrays (LFA) for an improved quality control in solar cell production lines, in Proceedings of the 19th European Photovoltaic Solar Energy Conference, Paris, France, 2004, pp.25912594.

[5] F.C. Krebs, K.O. Sylvester-Hvid and M. Jorgensen, A self-calibrating led-based solar test platform, Prog Photovoltaics Res Appl, vol. 9999, 2010.

[6] Strama MPS GmbH, Sun simulator for PV modules with integrated annealing function, vol.2010.

[7] T.Swonke.and U.Hoyer, Concept for a real AM1.5 simulator based on LED-technology and survey on different types of solar simulators, in Proceedings of the 24th European Photovoltaic Solar Energy Conference, Hamburg, Germany, 2009, pp. 3377-3379.

[8] B. H. Hamadani, K. Chua, J. Roller, M. J. Bennahmias, B. Campbell, H W. Yoon, B. Dougherty, Towards realization of a large-area light-emitting diode-based solar simulator, in Prog Photovoltaics. Res Appl, vol 1099159X, 2012.

[9] A.Lo, M. Despeisse, R. Thron, C. Ballif, An hybrid LED/Halogen largearea solar simulator allowing for variable spectrum and variable illumination pulse shape, in Proceedings of the 25th European Photovoltailc Solar Energy Conference and Exhibition, Valencia, Spain, 2012, pp. 4232-4235. 